\title{
Glioblastoma of the optic chiasm
}

\author{
F. B. GIBBERD, T. N. MILLER, AND A. D. MORGAN \\ From the Westminster Hospital and Medical School, London
}

Gliomas can arise in the optic pathways between the bulb and the lateral geniculate bodies. Their clinical behaviour is not only related to the degree of malignancy, but is also influenced by the site of origin. When they arise in the optic nerve they are often relatively benign. They are usually unilateral and involvement of the chiasm is not very common (Tym, I96ı; Chutorian, Schwartz, Evans, and Carter, I964; Hoyt and Baghdassarian, 1969; Davis, I940; Reese, 1956). However, those arising at the chiasm often spread to both optic nerves (Chutorian and others, I964; Russell, I971).

The majority of optic nerve gliomas occur in children under the age of io years (Chutorian and others, 1964) and they are rare in adults (Fowler and Matson, r957). In the case described below, the tumour arose in the optic chiasm of a 40 -year-old woman.

\section{Case report}

The patient was a Greek woman born in r929. The vision of her right eye started to deteriorat $\varrho \overrightarrow{0}$ in 1965 , and right choroidoretinitis was noted. In March, 1969, she developed bifrontal headaches $\omega$ initially relieved by aspirin but becoming progressively more severe. In July, 1969, she developedo bilateral visual impairment, intellectual deterioration, and dysphasia.

On admission to hospital in late July, I969, she was confused and disorientated.

\section{Examination}

There was papilloedema of the left fundus but both discs were pale; the retinae showed old choroido-retinitis possibly secondary to toxoplasmosis. The pupils did not react to light. She was blind in the right eye and could count fingers with the left eye. There was a slight left ptosis, and a right upper motor neurone facial weakness with bilateral extensor plantar responses. Tendon reflexes were normal. Blood pressure $145 / 95$. The rest of the examination gave normal results.

\section{Investigations}

Haemoglobin, white blood count, erythrocyte sedimentation rate, serum calcium, and electrolytes were normal. Erosion of the posterior clinoid processes was seen on radiography of the skull. An electroencephalogram showed a generalized abnormality with bursts of o-2 c.p.s. delta activity, as might occur in a deep midline or posterior fossa lesion. Tests of thyroid function in vitro were in the low normal range. Arteriography showed upward displacement of the proximal portion of the basilar artery. The cerebrospinal fluid was under a pressure of $270 \mathrm{~mm}$. and contained 4 lymphocytes per cu. mm. and $90 \mathrm{mg}$. per cent. protein. Pandy's test was strongly positive. At air encephalography the anterior end of the third ventricle could not be filled.

Course

The patient's condition gradually deteriorated and the temperature rose to $103^{\circ} \mathrm{F}$. She had scattered rhonchi at the bases of both the lungs, but no further central nervous system signs. Although the chest condition did not appear to progress, the temperature rose disproportionately to the other physical signs, and hypothalamic involvement was diagnosed. 


\section{Termination}

The patient died in August, I969, the immediate cause of death being bronchopneumonia.

\section{Pathology}

Externally the brain showed generalized compression, most marked in the right posterior parietal region. The suprasellar region was occupied by enormously thickened optic nerves, each of which was more than a centimetre in diameter, and infiltrated with tumour. The growth extended back into the optic chiasm, but did not involve the pituitary gland, which was free from the tumour and of normal size. There was erosion of the posterior clinoid processes of the sella turcica. The anterior surface of the pons was flattened abruptly but there was no cerebellar coning. The neoplastic process stopped at the optic foramina and the appearance of the optic nerves within the orbital cavities was normal.

There was a well-circumscribed firm haemorrhagic tumour lying between the floor of the third ventricle and the pituitary body, without invasion of either. The tumour measured $3.6 \times 3.2 \times 3.0 \mathrm{~cm}$., and its diameters crossed at the site of the normal optic chiasm (Figure). Growth extended down the intracranial portion of both optic nerves as far as the optic foramina. There were areas of recent necrosis and haemorrhage, with a small deposit in the floor of the fourth ventricle at the level of the medulla oblongata, deforming the aqueduct. Microscopically it was an astrocytoma grade II, with spindleshaped cells of fairly uniform appearance, lightly-staining nuclei, and no miotic figures. The optic nerves did not show evidence of demyelination or other disease beyond the limits of invasion, i.e. within the orbits.

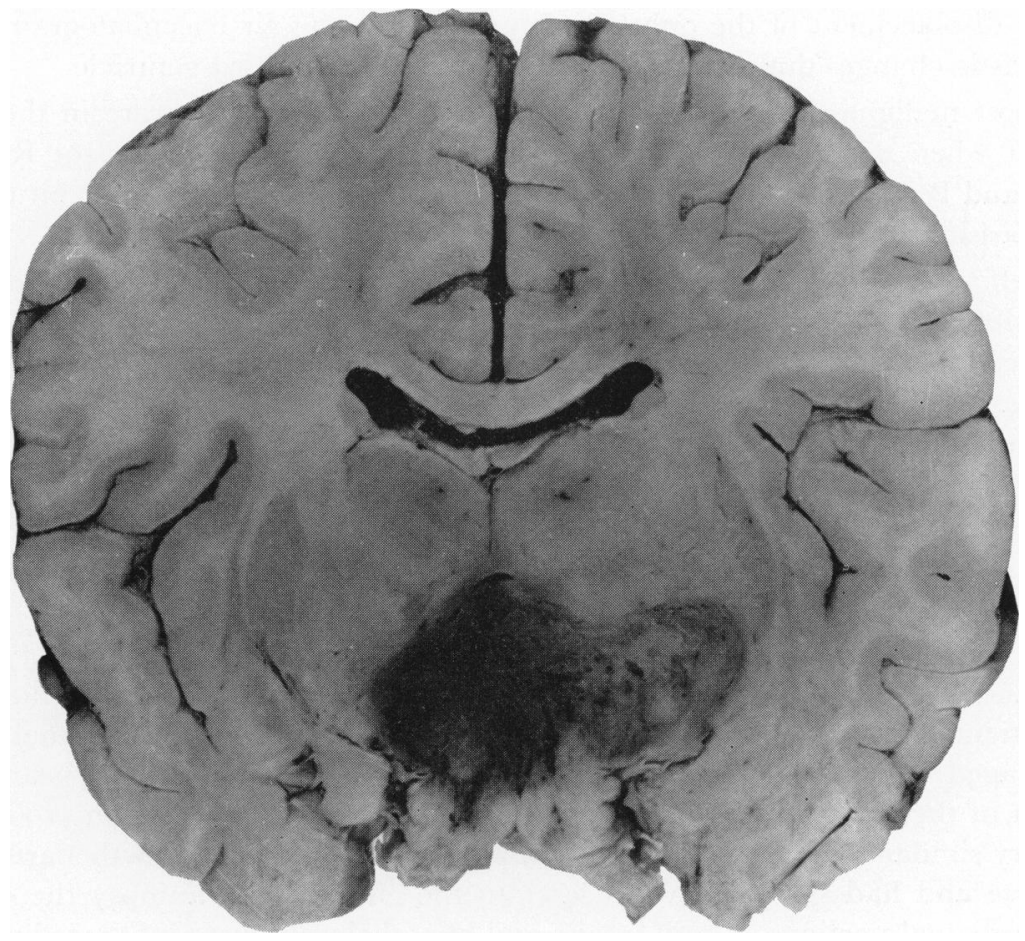

FIGURE The tumour is seen in the optic chiasm compressing the ventricle and growing into the optic nerves 


\section{Discussion}

The signs and symptoms could all be explained by the glioma except for the bilateral choroidoretinitis. There was no obvious aetiology for the glioma, although in children about 50 per cent. of cases are associated with neurofibromatosis (Tym, I96I). The peak $\vec{\Rightarrow}$ incidence of optic nerve glioma is between the second and sixth year (Chutorian and others, I 964) and 75 per cent. occur in children under the age of Io years (Posner and Horrax, 흠 r 948). The oldest patient on record was aged 79 (Condon and Rose, r 967). Hudson $\frac{\bar{m}}{\bar{a}}$ ( I 9 I2) described cases of degenerative gliomatosis of the optic nerve which was probably $\mathbb{D}$ the same: of I I I cases, 69 were in the first decade of life, 29 in the second, six in the third, कs three each in the fourth and fifth, and one in the sixth.

The signs occurring in particular cases are related to the site of the lesion. Gliomas of the optic pathways may be intraorbital, intracranial, or both (Fowler and Matson, I 957). In our case the tumour did not reach the orbit. As it arose at the chiasm, it is not surprising that the tumour had grown equally down the two optic nerves. Usually the growth extends forward through the optic foramina which become enlarged and eye $\overrightarrow{0}$ movements may become limited by distortion of the structures in the orbit. Associated with this there will be a progressive non-pulsatile proptosis (van Buren, van Poppen, and Horrax, 1957), optic atrophy and papilloedema, and occasionally the tumour itself may be seen at ophthalmoscopy. Because our patient's lesion did not extend into the orbit none of the above features occurred. The optic foramina were not enlarged at autopsy. This may be because the tumour grew so quickly that there was insufficient $\stackrel{\mathbb{\Phi}}{工}$ time for the bone to be eroded, but this alone would not explain the abrupt cessation of $\overrightarrow{0}$ growth in both optic nerves at the foramen. Even if the bone had not been eroded, the growth might have caused nerve enlargement in the orbit. The carotid arteriogram dif not show displacement of the ophthalmic artery, but the air encephalogram showed the characteristic changes due to upward displacement of the third ventricle.

The most malignant gliomas, the glioblastomas, are relatively rare in the optic pathways, but when they do occur they are usually in adults (Saebo, I949; Russell, I97ı; Mattson and Peterson, I966). With glioblastomas it is particularly difficult to distinguish tumours arising in the optic chiasm and the hypothalamus.

Verhoeff (1932) described the spread of gliomas along the optic nerve but did not mention their possible spread into the optic chiasm. Involvement of the chiasm has been reported in advanced cases of optic glioma (Tym, I96r ; Chutorian and others, I964; Hoyt and Baghdassarian, I969). It may be difficult to distinguish those arising in the optic nerves and spreading back into the chiasm from those arising in the chiasm. However, when glioma arises in the optic chiasm, it is more likely to infiltrate the hypothalamus and walls of the third ventricle (Russell, I97 I).

In the first large series of tumours involving the optic nerve, Hudson (I9I2) described fifteen cases with intracranial extension, of which thirteen involved the chiasm. Although the exact diagnosis in all these cases is uncertain they were probably all gliomas. Martin and Cushing (1923) described seven cases of optic nerve and chiasm gliomas, two in patients aged 56 and 25. Foerster and Gagel ( I 93 I) described chiasmal involvement in a man aged 30 years and Condon and Rose ( 1967$)$ in a patient aged 79 years. The rate of growth in these cases varied considerably, but Mattson and Peterson ( 1966) described a case very similar to ours in a 59-year-old patient in whom the growth started in the left optic nerve and had spread 6 weeks later to the chiasm. At autopsy the optic chiasm and the proximal portions of both nerves and hypothalamus were infiltrated with tumour. , 
Considering the relative infrequency of optic nerve gliomas in adults, it is remarkable how often cases of chiasmal involvement have been reported in adults. Nevertheless, chiasmal involvement in optic nerve gliomas of childhood was described by Chutorian and others ( 1964 ) in thirty children under the age of 16 years and by others (Tym, I96 1 ; Davis, 1940). Davis described a case in which there were tumours in both the brain and optic nerve, but there was no anatomical connection between them and it was unlikely that one tumour had spread from the other.

The prognosis for optic gliomas is good although they can occasionally be highly malignant (Mattson and Peterson, r966). The fact that the chiasm is involved does make the prognosis worse (Fowler and Matson, I957; Chutorian and others, I964). Hoyt and Baghdassarian, ( 1969 ) reported a series of 36 patients, ten of whom died, but as with most reports of optic gliomas the majority were children. Four of his patients, like ours, had blockage of the cerebrospinal fluid pathways, at the level of the third ventricle.

In conclusion, this patient demonstrates the progression of a malignant glioma, probably arising in the optic chiasm, into both optic nerves and the hypothalamus. There was absence of neurofibromata and rapid growth of the glioma.

\section{Summary}

The case is reported of a $4^{0}$-year-old woman with an astrocytoma of the optic chiasm. The glioma had spread into both optic nerves as far as the optic foramina. The third ventricle was displaced but not invaded and the pituitary was free of tumour.

\section{References}

Chutorian, A. M., SchWARTz, J. F., EVANS, R. A., and GARTer, s. (ig64) Neurology, (Minneap.), r4, 83 CONDON, J. R., and rose, F. C. (1967) Brit. J. Ophthal., 51, 703

DAVis, F. A. (1940) Arch. Ophthal. (Chicago), 23, 735 and 975

FOERSTER, O., and GAGEL, o. (I93I) Z. Neurol., r36, 335

FOWler, F. D., and MAtSon, D. D. (I957) J. Neurosurg., 14, 515

hOYt, W. F., and BAghdassarian, s. A. (ig69) Brit. J. Ophthal., 53, 793

Hudson, A. C. (1912) Roy. Lond. ophthal. Hosp. Rep., 18, 317

martin, P., and cushing, H. (1923) Arch. Ophthal. (N.Y.), 52, 209

mattson, R. h., and peterson, e. W. (ig66) J. Amer. med. Ass., 196, 799

PoSNer, M., and horrax, G. (1948) Arch. Ophthal. (Chicago), 40, 56

REESE, A. B. (I956) "Atlas of Tumor Pathology", Section X, Fascicle 38, "Tumors of the Eye and

Adnexa", pp. 63-65. Armed Forces Institute of Pathology, Washington, D.C.

RUSSEll, D. S., and Rubinstein, L. J. (I97I) "Pathology of Tumours of the Central Nervous System", 3rd ed. Arnold, London.

SAEBg, J. (1949) Brit. 7. Ophthal., 33, 70 I

TYM, R. (196I) Brit. 7. Surg., 49, 322

VAN BUREN, J. M., POPPEN, J. L., and horraX, G. (1957) Brain, 80, 139

VERHOEFF, F. H. (I932) "Tumours of the optic nerve" in "Cytology and Cellular Pathology of the

Nervous System”, ed. W. Penfield, vol. 3, p. I029. Hoeber, New York. 